\title{
1 On the treatment effect heterogeneity of antidepressants in major depression.
}

2

3

4

5

13 Corresponding author:

14 Dr. med. Constantin Volkmann

15 Department of Psychiatry and Psychotherapy

16 Charité - Universitätsmedizin Berlin, Charité Campus Mitte

17 Charitéplatz 1

1810117 Berlin

19 Tel: +4930450617406

20 Email: constantin.volkmann@charite.de

21

22

23

24 Tables: 1

25 Figures: 6

26 Word count: 5685 
medRxiv preprint doi: https://doi.org/10.1101/2020.02.20.19015677; this version posted April 7, 2020. The copyright holder for this preprint (which was not certified by peer review) is the author/funder, who has granted medRxiv a license to display the preprint in perpetuity.

It is made available under a CC-BY 4.0 International license.

\section{Abstract}

28 Background: The average treatment effect of antidepressants in major depression was 29 found to be about 2 points on the 17-item Hamilton Depression Rating Scale, which lies below clinical relevance. Here, we searched for evidence of a relevant treatment effect heterogeneity that could justify the usage of antidepressants despite their low average treatment effect.

Methods: Bayesian meta-analysis of 169 randomized, controlled trials including 58,687 patients. We considered the effect sizes log variability ratio (InVR) and log coefficient of variation ratio ( $\mathrm{InCVR}$ ) to analyze the difference in variability of active and placebo response. We used Bayesian random-effects meta-analyses (REMA) for InVR and InCVR and fitted a random-effects meta-regression (REMR) model to estimate the treatment effect variability between antidepressants and placebo.

Results: The variability ratio was found to be very close to 1 in the best fitting models (REMR: 95\% HPD [0.98, 1.02], REMA: 95\% HPD [1.00, 1.02]). The between-study variance $\mathrm{T}^{2}$ under the REMA was found to be low (95\% HPD [0.00, 0.00]). Simulations showed that a large treatment effect heterogeneity is only compatible with the data if a strong correlation between placebo response and individual treatment effect is assumed.

Conclusions: The published data from RCTs on antidepressants for the treatment of major depression is compatible with a near-constant treatment effect. Although it is impossible to rule out a substantial treatment effect heterogeneity, its existence seems rather unlikely. Since the average treatment effect of antidepressants falls short of clinical relevance, the current prescribing practice should be re-evaluated.

Keywords: Major depressive disorder, Antidepressants, Individual treatment effect, 
medRxiv preprint doi: https://doi.org/10.1101/2020.02.20.19015677; this version posted April 7, 2020. The copyright holder for this preprint (which was not certified by peer review) is the author/funder, who has granted medRxiv a license to display the preprint in perpetuity. It is made available under a CC-BY 4.0 International license.

\section{Introduction}

66

Depression is one of the most frequent psychiatric disorders and poses a major burden for individuals and society; it affects more than 300 million people worldwide and is ranked as the single largest contributor to disability [1]. The first-line treatment usually consists of psychotherapy and/or pharmacotherapy with antidepressant drugs [2, 3]. Within the last decades, the number of prescriptions of antidepressants has continuously increased in several regions of the world [4,5]. However, whether antidepressants are effective in the treatment of major depression has been a highly controversial debate for many years [6-9]. A recent meta-analysis by Cipriani et al. comprising 522 randomized, controlled trials (RCTs) of 21 antidepressants in $116 \square 477$ participants reported that all antidepressants were more effective than placebo in reducing depressive symptoms [10]. In contrast, the authors of a recent re-analysis criticised this meta-analysis for not taking into account several biases, such as publication bias [12]. They concluded that "the evidence does not support definitive conclusions regarding the efficacy of antidepressants for depression in adults, including whether they are more efficacious than placebo for depression". Albeit these contradictory conclusions, both analyses used the same dataset. The so-called average treatment effect, which measures the difference in mean outcomes between active and control group, was about 2 points on the 17-item Hamilton Depression Rating Scale (HAMD-17) [13] in this dataset [12]. According to Leucht et al. [14], a reduction of up to 3 points on the HAMD corresponds to "no change" in the Clinical Global Impressions Improvement Scale (CGI-I) [15] and the assumed threshold of clinical significance is 7 points [16]. Thus, a reduction of 2 points on the HAMD is not detectable by the treating physician and is presumably clinically irrelevant. Crucially, Munkholm et al. [12] reported the average treatment effect as an outcome parameter, whereas Cipriani et al. [10] reported the odds ratio (OR) of "response rates", signifying the fraction of patients crossing the rather arbitrary threshold of $50 \%$ in symptom reduction ("responders"). This approach translates into a number-needed-to-treat (NNT) of around 8-10 for "response" [17].

94

\section{Categorisation of continuous variables}

96 Categorising patients into "responders" and "non-responders" based on crossing an arbitrary 97 threshold on a continuous scale has frequently been criticised by statisticians as it may lead 98 to an artificial inflation of the measured treatment effect and to a loss of power [18, 19]. It 99 may create the illusion of a subgroup of patients that benefit particularly well from a given 
medRxiv preprint doi: https://doi.org/10.1101/2020.02.20.19015677; this version posted April 7, 2020. The copyright holder for this preprint (which was not certified by peer review) is the author/funder, who has granted medRxiv a license to display the preprint in perpetuity.

It is made available under a CC-BY 4.0 International license .

100 treatment where none exists. However, a NNT of 8 is compatible with every patient having

101 the exact same treatment effect of 2 points on the HAMD-17 [12, 20]. Only if a substantial so-

102 called treatment effect heterogeneity exists, meaning that there are true "responders" and

103 "non-responders", the calculation of response rates may be legitimate and the average

104 treatment effect may not be an appropriate outcome measure. However, in the absence of

105 clear evidence for a relevant treatment effect heterogeneity, the average treatment effect is

106 the best predictor of the individual treatment effect [20, 21].

107

108 Treatment effect heterogeneity

109 Treatment effect heterogeneity describes the extent to which a treatment might affect

110 different individuals differentially. In other words, some patients may benefit a lot, others may

111 be harmed by a given treatment, possibly resulting in a null finding when only considering the

112 average treatment effect in clinical trials. However, the existence of a clinically relevant

113 treatment effect heterogeneity, albeit widely believed and intuitively plausible, has not been

114 shown yet.

115

116

117

118 


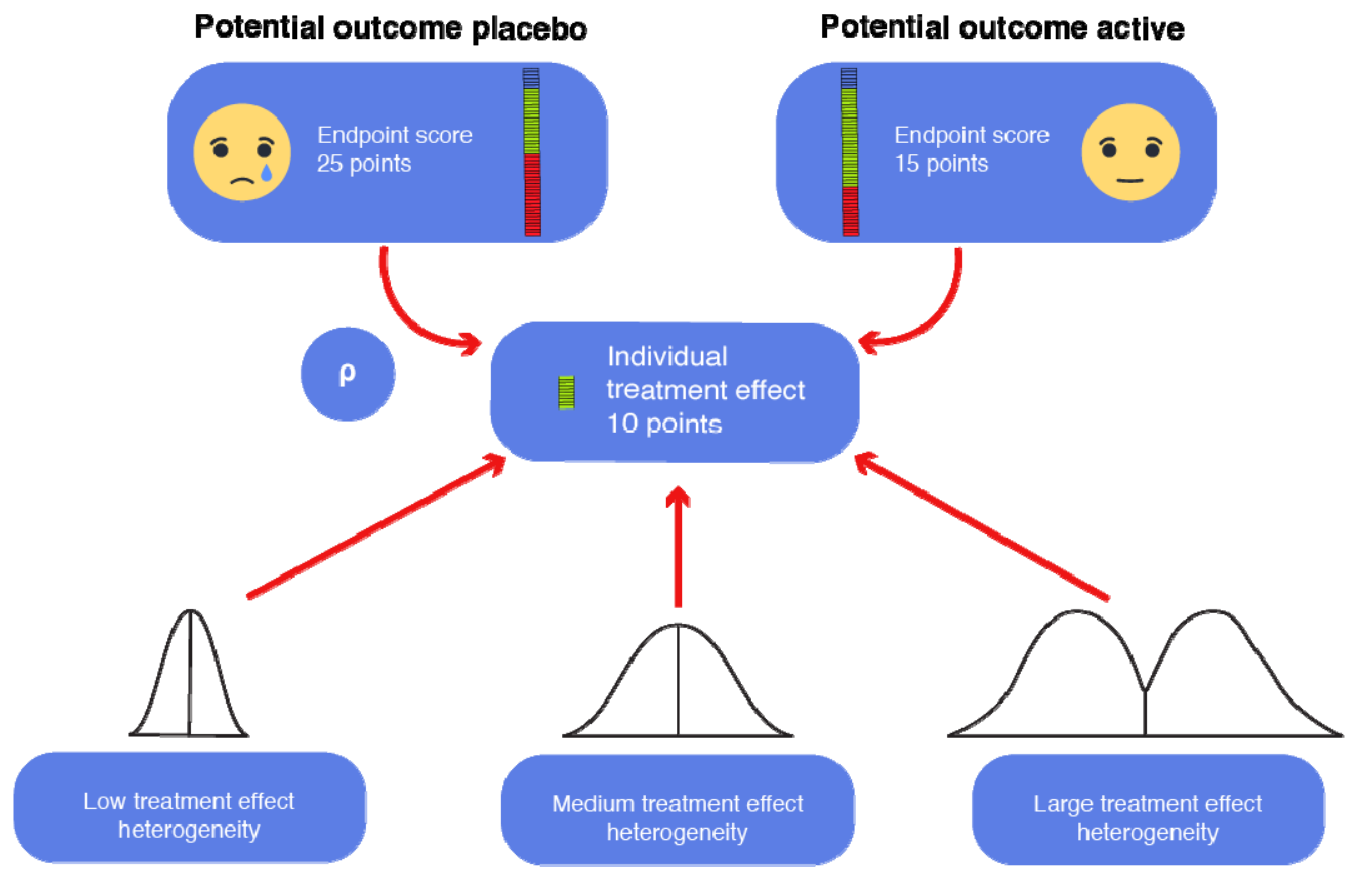

120 Figure 1: Visualization of a hypothetical patient in a randomized placebo-controlled trial. The

121 patient is randomized to either the placebo or the active arm, corresponding to two

122 hypothetical "potential outcomes". Only one of which can ever be observed, as a single

123 patient cannot receive both placebo and the active intervention at the same time. The

124 difference between the two potential outcomes corresponds to the "individual treatment 125 effect" of the intervention (here, a clinically relevant difference of 10 HAMD-17 points). The

126 individual treatment effect is unobservable and can be imaged to be drawn from hypothetical

127 distributions of the treatment effect. The variance of this distribution corresponds to the 128 treatment effect heterogeneity. The factor $\rho$ is the correlation between the placebo response 129 and the individual treatment effect. Here, we assume that a given patient has a fixed 130 individual treatment effect. 
medRxiv preprint doi: https://doi.org/10.1101/2020.02.20.19015677; this version posted April 7, 2020. The copyright holder for this preprint (which was not certified by peer review) is the author/funder, who has granted medRxiv a license to display the preprint in perpetuity.

It is made available under a CC-BY 4.0 International license.

131

132 Investigation of treatment effect heterogeneity

133 Simply labeling patients as "responders" and "non-responders" based on crossing an

134 arbitrary threshold on a continuous outcome scale is not a valid way to investigate variation

135 in individual treatment effect [22]. In order to assess treatment effect heterogeneity from the

136 data of parallel group trials, the comparison of variances between the active and the control

137 condition has been proposed [22, 23]. Here, an increase in variance in the active group might

138 be a signal of a variation in the individual treatment effect [22].

139 Following a recent publication by Winkelbeiner et al. [21], analyzing differences in variances

140 in 52 randomized, placebo-controlled antipsychotic drug trials, the present analysis aimed to

141 assess the evidence for individual antidepressant drug response using the open dataset of

142 the largest meta-analysis of the efficacy of antidepressants in major depressive disorder

143 [10].

144 Here, we addressed the following research question: What is the evidence for a relevant 145 treatment effect heterogeneity of antidepressants in the treatment of depression that justifies

146 their usage despite the lack of a clinically relevant average treatment effect?

147

148 Methods

149

150 Data Acquisition

151 We obtained the dataset of the meta-analysis by Cipriani et al. [10] from the Mendeley 152 database (https://data.mendeley.com/datasets/83rthbp8ys/2). This study included all RCTs 153 comparing 21 antidepressants with placebo or another active antidepressant as oral 154 monotherapy for the acute treatment of adults ( $\geq 18$ years old and of both sexes) with a 155 primary diagnosis of major depressive disorder according to standard operationalized 156 diagnostic criteria (Feighner criteria, Research Diagnostic Criteria, DSM-III, DSM-III-R, DSM-

157 IV, DSM-5, and ICD-10). For further details on the inclusion criteria and study characteristics, 158 see the original study [10].

159

Data extraction and processing

161 Of the total of 522 studies we kept the 304 that included a placebo arm. We excluded all 162 studies for which the reported endpoint did not represent the change from baseline, leaving 163 us with a total of 169 studies for the analysis (see PRISMA flow diagram, supplementary 164 data, figure 1). We extracted both the mean and the standard deviation of pre- and post165 treatment outcome difference scores (the "response"). The studies included in the data set 166 comprised 8 different depression scales, namely HAMD-17, HAMD-21, HAMD-24, HAMD 167 unspecified, HAMD-29, HAMD-31, Montgomery-Åsberg Depression Rating Scale (MADRS) 
medRxiv preprint doi: https://doi.org/10.1101/2020.02.20.19015677; this version posted April 7, 2020. The copyright holder for this preprint (which was not certified by peer review) is the author/funder, who has granted medRxiv a license to display the preprint in perpetuity.

It is made available under a CC-BY 4.0 International license .

168 [24] and IDS-IVR-30 [25, 26]. Studies with different treatment arms were aggregated 169 according to the recommendation of the Cochrane Collaboration [27]. In this manuscript, we 170 define response as pre-post-difference of a given outcome scale.

171

Statistical Analysis

173 We considered two different effect size statistics as suggested by Nakagawa et al. [28] to analyze the difference in variability of active and placebo response.

1. The log variability ratio

2. The log coefficient of variation ratio

These two effect sizes differ in the way they account for differences in means between the active and the placebo group. Whereas InVR assumes no correlation between concurrent changes in mean response and standard deviation of response, InCVR measures differences in variability between groups after accounting for differences in mean response. If the active and placebo arms have equal variance, a VR (or CVR) of 1 would be expected. A value greater than 1 indicates a larger variability in the active group.

A variability ratio that substantially differs from 1 implies a considerable treatment effect heterogeneity. Conversely, a VR of around 1 is compatible with a near-constant treatment effect but does not exclude the existence of treatment effect heterogeneity. It should be noted, that it is impossible to disprove the existence of a subgroup with a substantially greater than average effect. However, the magnitude of the treatment effect heterogeneity can be bounded by the distance of the variability ratio VR from the value 1 .

194 All statistical analyses were carried out in the programming language Python (version 3.7) 195 and the probabilistic programming language Stan (with pystan version 2.18.1.0 as a Python 196 interface). We used a Bayesian approach to fit all our models using weakly informative priors. Firstly, we used a Bayesian random-effects meta-analyses (REMA) for the two effect statistics InVR and InCVR. Secondly, we used a Bayesian random-effects meta-regression (REMR) to fit the InVR effect statistic with the natural logarithm of the response ratio (InRR) as a regressor [28], which is defined as: 
medRxiv preprint doi: https://doi.org/10.1101/2020.02.20.19015677; this version posted April 7, 2020. The copyright holder for this preprint (which was not certified by peer review) is the author/funder, who has granted medRxiv a license to display the preprint in perpetuity.

It is made available under a CC-BY 4.0 International license .

205

206

207

208

209

210

211

212

213

214

215

216

217

218

219

220

221

222

$$
\begin{aligned}
& \mu \sim \operatorname{Cauchy}(0,1) \\
& \tau \sim \operatorname{Half}-\operatorname{Cauchy}(0,1)
\end{aligned}
$$

\section{Random-effects meta-regression (REMR)}

226

227

228

229

230

231

232

$$
\begin{array}{ll} 
& \ln V R_{i} \sim N\left(Y_{i}, s^{2}{ }_{\ln V R_{i}}\right) \\
& Y_{i}=\mu+\beta * X_{i}+\eta_{i} \\
233 \quad & \eta_{i} \sim N\left(0, \tau^{2}\right) \\
& X_{i} \sim N(0,100)
\end{array}
$$


medRxiv preprint doi: https://doi.org/10.1101/2020.02.20.19015677; this version posted April 7, 2020. The copyright holder for this preprint (which was not certified by peer review) is the author/funder, who has granted medRxiv a license to display the preprint in perpetuity.

It is made available under a CC-BY 4.0 International license.

$$
\ln R R_{i} \sim N\left(X_{i}, s^{2}{ }_{\ln R R_{i}}\right)
$$

234

235 We specified the following weakly-informative hyper-priors:

236

$$
\begin{aligned}
& \mu \sim \operatorname{Cauchy}(0,1) \\
& \beta \sim \operatorname{Cauchy}(0,1) \\
& \tau \sim \operatorname{Half}-\operatorname{Cauchy}(0,1)
\end{aligned}
$$

237

\section{Simulation experiments}

239 For each simulation, the response under placebo and the response under treatment were 240 simulated for 1000 patients. The response under placebo was drawn from a right skewed 241 distribution with mean and standard deviation of 8.8 and 7.7 points on the HAMD-17 scale

242 (based on Cipriani data [10]), respectively. For each patient, an outcome under treatment 243 was computed from a mixed Gaussian distribution with a given $\mathrm{SD}_{\mathrm{TE}}$, where the outcome 244 under placebo and the individual treatment effect were required to be correlated by the 245 correlation coefficient $\rho$.

246 This yielded a potential outcome under placebo and a potential outcome under active 247 treatment for every patient with a corresponding individual treatment effect (see figure 1 for 248 illustration). Half of the patients were then randomly selected for treatment, the other half was 249 assigned to placebo. Note that only one of these two outcomes can be observed in a real 250 experiment.

251

\section{Results}

253

254

\section{Study selection}

255 As mentioned above, we included 169 placebo-controlled studies that reported mean and 256 standard deviation of change in depression scores. These studies included data on 58,687 257 patients treated with 21 different antidepressants.

Correlation between mean and standard deviation of depression scores

260 In order to identify the more appropriate effect size (VR or CVR), we investigated the linear 261 association between the logarithm of the mean response scores and the logarithm of their 262 standard deviation using a varying intercept model, where the intercepts were allowed to 263 vary between studies with different depression scales. Fitting a Bayesian varying intercept 264 regression model with measurement error with InMean as independent variable and InSD as 265 dependent variable, we get a posterior mean for the slope coefficient of 0.10 with a $95 \%$ 266 HPD (highest probability density) interval of $[0.04,0.16]$. This can be interpreted as a weak 
medRxiv preprint doi: https://doi.org/10.1101/2020.02.20.19015677; this version posted April 7, 2020. The copyright holder for this preprint (which was not certified by peer review) is the author/funder, who has granted medRxiv a license to display the preprint in perpetuity.

It is made available under a CC-BY 4.0 International license .

267 correlation between InMean and InSD. We remark that simply computing the correlation of 268 the two quantities without paying attention to the correct weighting and the different scales in 269 the data would yield an overestimated slope coefficient of 0.25 (see supplementary table 1).

270

Fitted varying intercept regression
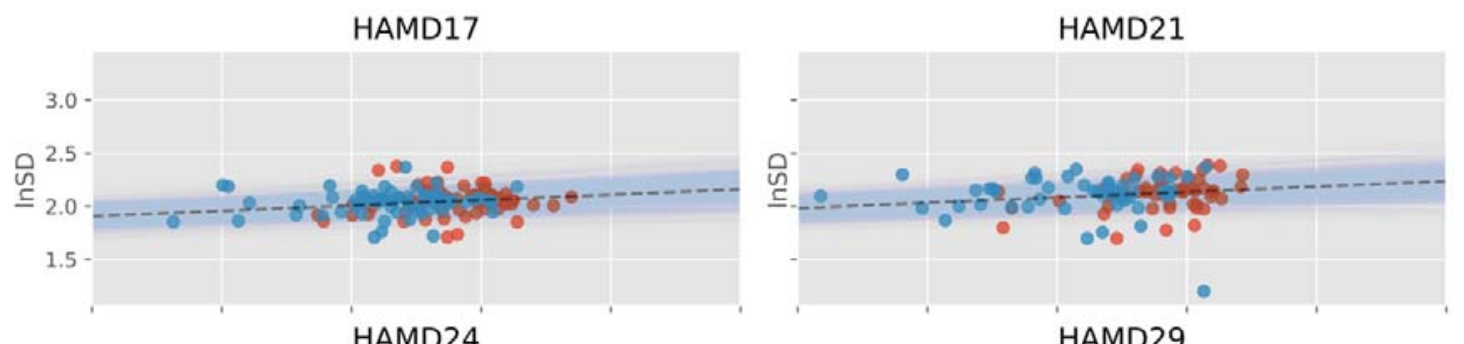

HAMD29
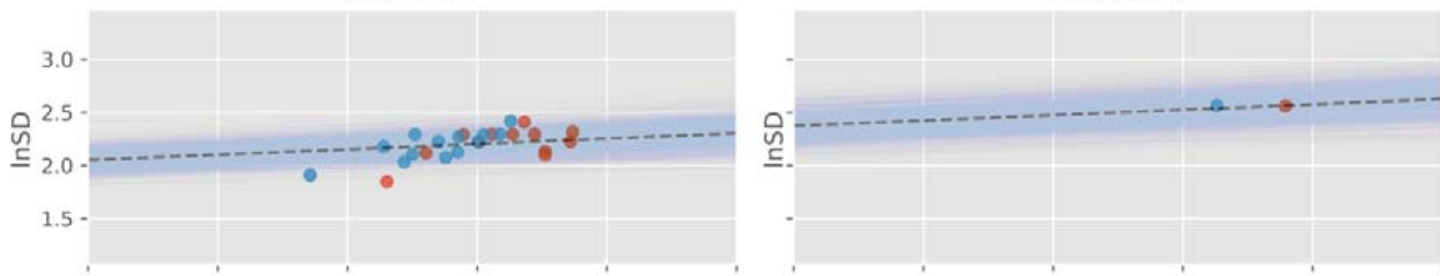

HAMD31
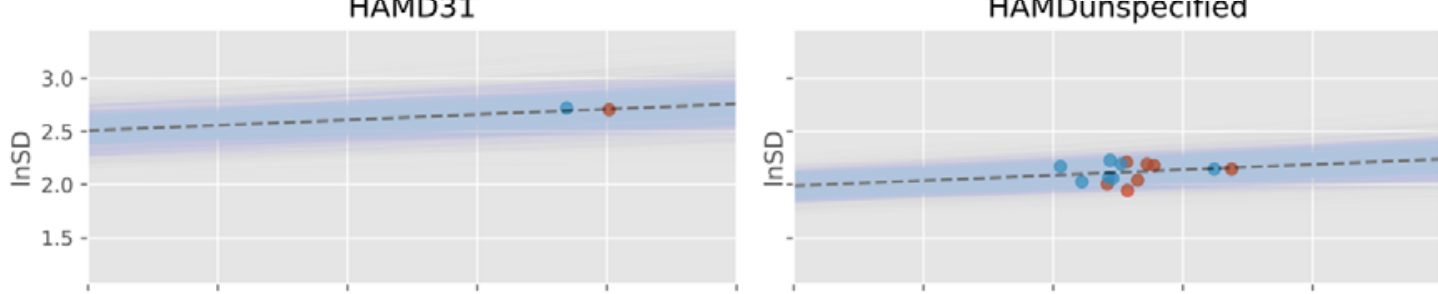

IDS-IVR-30

MADRS
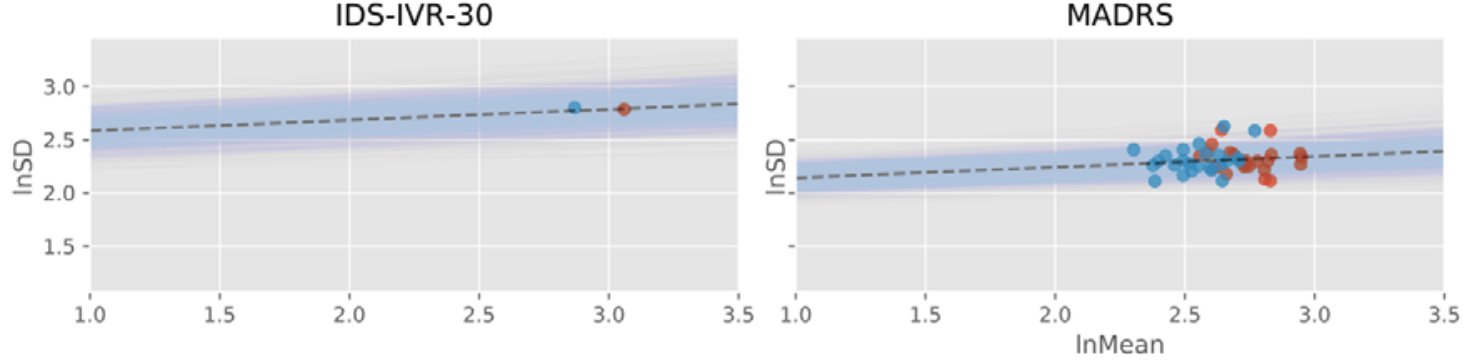

271

Figure 2: Linear association between InMean and InSD using a varying intercept model,

273 where the intercepts are allowed to vary between studies with different depression scales.

274 Red dots represent active groups, blue dots represent placebo groups.

275

276

Log variability ratio (InVR) and log coefficient of variation (InCVR) models

277 In order to estimate the difference in variability between antidepressant and placebo

278 response, we modelled the InVR effect size using a Bayesian random effects model as

279 heterogeneity between studies may be expected. The posterior mean estimate for the

280 variability ratio was 1.01 , with the $95 \%$ highest posterior density (HPD) interval ranging from 
medRxiv preprint doi: https://doi.org/10.1101/2020.02.20.19015677; this version posted April 7, 2020. The copyright holder for this preprint (which was not certified by peer review) is the author/funder, who has granted medRxiv a license to display the preprint in perpetuity.

It is made available under a CC-BY 4.0 International license .

2811.00 to 1.02 . The InVR effect size assumes no correlation between InMean and InSD and

282 may give biased results if such a correlation exists. In the presence of a positive correlation

283 between mean and standard deviation, Nakagawa et al. [28] suggest that the InCVR may be

284 the more appropriate effect size to investigate the difference in variability between the active

285 and control. The InCVR REMA showed a reduction in the coefficient of variation in the active

286 versus the placebo group (posterior mean estimate for CVR: 0.82, 95\% HPD [0.80,0.84]).

287

Random-effects meta-regression

289 Finally, we used a Bayesian random effects meta-regression (REMR). The advantage of this

290 model over the InVR and InCVR meta-analyses is that we are not forced to make rigid 291 assumptions about the association between the InMean and InSD, as the strength of this 292 relationship is estimated directly from the data. Fitting this model, we obtained posterior 293 statistics for the $\mu$ and $\beta$ coefficients. The posterior mean estimate for $e^{\mu}$ was 1.00 (95\% HPD $294[0.98,1.02])$ and that for $\beta 0.04$ (95\% HPD [-0.03,0.12]), where we can (roughly, up to

4. $V R \approx e^{\mu} * R R^{\beta} \quad(\ln V R \approx \mu+\beta * \ln R R)$

Note that the InVR REMA corresponds to a InVR REMR with a $\beta$ coefficient set to 0 , whereas the InCVR REMA corresponds to a InVR REMR with a $\beta$ coefficient set to 1 . The REMR model learns the $\beta$ coefficient and its posterior HDP interval is equal to $0.04[-0.03,0.12]$ suggesting that the InVR REMA is a more appropriate model than the InCVR REMA.

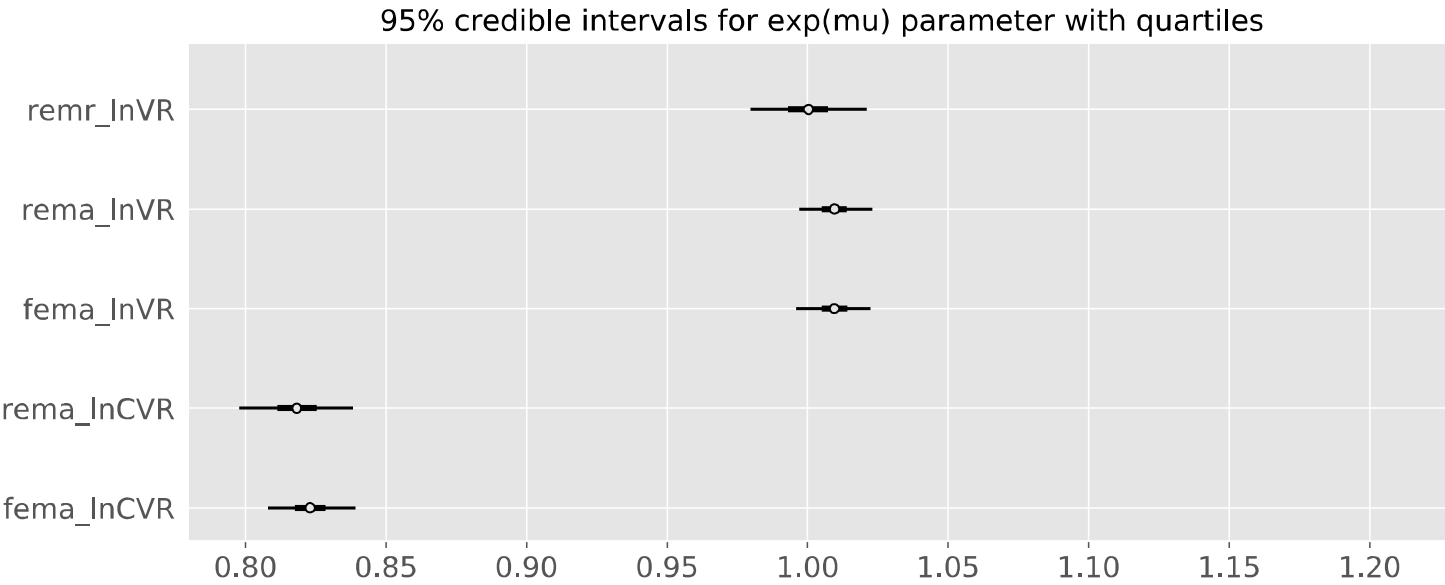

Figure 3: Posterior credible intervals for the $\exp (\mu)$ parameter for the different models.

306 REMA: random-effects meta-analysis. FEMA: fixed-effects meta-analysis. REMR: random307 effects meta-regression. Note that the results are very similar for the REMR and the InVR 308 meta-analyses. 
medRxiv preprint doi: https://doi.org/10.1101/2020.02.20.19015677; this version posted April 7, 2020. The copyright holder for this preprint (which was not certified by peer review) is the author/funder, who has granted medRxiv a license to display the preprint in perpetuity.

It is made available under a CC-BY 4.0 International license.

Between-study heterogeneity

311 The between-study variance $\mathrm{T}^{2}$ under the REMA was found to be low for both InVR $(95 \%$

312 HPD [0.00,0.00]) and InCVR (95\% HPD for $\left.\mathrm{T}^{2}[0.00,0.01]\right)$. Indeed, applying a fixed effects

313 model instead of the REMA for the purpose of sensitivity analysis yielded similar results for

314 the overall mean estimates of InVR and InCVR.

\section{Performance comparison of the different models}

317 In order to compare the performance of the different models applied, we used the so-called

318 widely applicable information criterion (WAIC). This method estimates the pointwise 319 prediction accuracy of fitted Bayesian models. Here, higher values of WAIC indicate a better out-of-sample predictive fit ("better" model). We refer to Vehtari et al. [31] for more details on WAIC. Figure 4 shows the logWAIC for the different models.

Model comparison based on WAIC with log scale

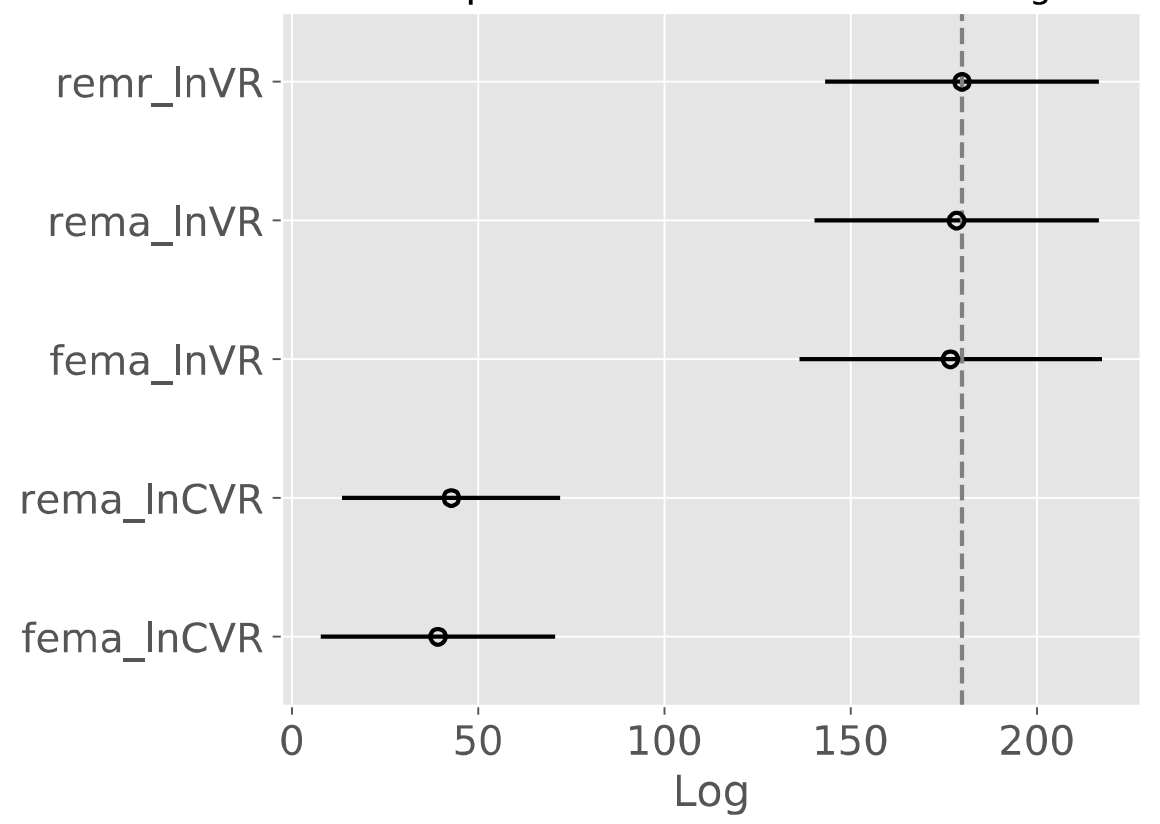

324 Figure 4: Widely applicable information criterion (WAIC) depicted on a logarithmic scale.

325 Higher values signify a better predictive fit of the underlying model. Bars indicate standard 326 errors. REMA: random-effects meta-analysis. FEMA: fixed-effects meta-analysis. REMR: 327 random-effects meta-regression.

We observed that the InVR REMA and the InVR REMR outperformed the InCVR REMA with respect to the WAIC. The difference between the InVR REMA and the InVR REMR showed comparable performance with respect to the WAIC. 
medRxiv preprint doi: https://doi.org/10.1101/2020.02.20.19015677; this version posted April 7, 2020. The copyright holder for this preprint (which was not certified by peer review) is the author/funder, who has granted medRxiv a license to display the preprint in perpetuity.

It is made available under a CC-BY 4.0 International license .

Upper bound on the treatment effect heterogeneity

In order to investigate the compatibility of different assumptions regarding the treatment effect with the measured variability ratio, we use the following equation that was derived in [32]:
5. $V R^{2}-1=\frac{\left(S D_{t x}+\rho * S D_{p}\right)^{2}}{S D_{p}}-\rho^{2}$
$\rho^{2}$, where $t x=$ individual treatment effect

Note that the variable $\rho$ signifies the degree of correlation between the treatment effect tx and the response under placebo $\mathrm{p}$ (see figure 1) and is unobservable. Assuming that $\mathrm{VR}^{2}-1$ is smaller than some number $\varepsilon$, the above equation implies that:
6. $S D_{t x} \leq S D_{p} *\left(\sqrt{\left(\varepsilon+\rho^{2}\right)}-\rho\right)$

Using the Cipriani et al. dataset [10] we can estimate $S D_{p}$ to be equal to around 7.66 on the HAMD-17 scale. From our meta-analysis of the InVR effect statistic, we have that the 95th percentile of the posterior distribution of $e^{\mu}$ is 1.02 . This implies the following inequality:

$$
\text { 7. } S D_{t x} \leq 7.66 *\left(\sqrt{\left(0.04+\rho^{2}\right)}-\rho\right)
$$

This inequality tells us that if we assume any value $\rho \in[-1,1]$ (the correlation between the treatment effect and the response under placebo), we get an upper bound on the standard deviation of the treatment effect as above.

\section{Which distributions of the treatment effect are possible for a VR of nearly 1 ?}

Based on the above-mentioned formula 7, table 1 depicts different magnitudes of treatment effect heterogeneity compatible with a VR of 1.02 , which is the 95th percentile of our VR estimate.

The left column ("any distribution") of the table depicts the upper bound for the standard deviation of the treatment effect (the treatment effect heterogeneity) with a VR of 1.02. The upper bound for the treatment effect heterogeneity depends upon the population-level correlation $\rho$ between the "response under placebo" and the "individual treatment effect" (see figure 1). The results can be interpreted as follows: assuming a correlation $\rho$ between the individual treatment effect and the response under placebo of a given value in the table, we are $95 \%$ sure (under the assumptions of the meta-analytic model (REMA) of InVR) that the standard deviation of the treatment effect variable is smaller than the corresponding value of the second column in the table. Furthermore, assuming a minimally clinically relevant effect 
medRxiv preprint doi: https://doi.org/10.1101/2020.02.20.19015677; this version posted April 7, 2020. The copyright holder for this preprint (which was not certified by peer review) is the author/funder, who has granted medRxiv a license to display the preprint in perpetuity.

It is made available under a CC-BY 4.0 International license .

369 of 7 points on the HAMD-17 scale, the third column tells us the percentage of patients with a

370 medication effect at least as large for the largest possible standard deviation within the 95\%

371 credible interval. Note that these results are independent of the distribution of the treatment

372 effect (normal, binormal, etc.), as these results were derived analytically from the above-

373 mentioned formula (see formula 7).

374

375 The right column assumes a dichotomous treatment effect ("responder", "non-responder").

376 Here, "non-responders" are assumed to have treatment effect of 0 (placebo response =

377 antidepressant response), whereas "responders" have a fixed treatment effect $>0$. For a

378 given VR of 1.02, the percentage of "responders" and their respective "responder treatment

379 effect" depend upon the intra-individual correlation $\rho$ between the potential outcome placebo

380 response and individual treatment effect.

381

382

383

384

385

386

387

388

389

390

\begin{tabular}{rrrrr} 
& \multicolumn{2}{c}{ any distribution } & \multicolumn{2}{c}{ dichotomous response } \\
\hline & SD(TE) & \% > 7 HAMD & responder TE & \% responder \\
\hline-1.0 & 15.5 & 37.3 & 20.5 & 9.7 \\
-0.8 & 12.4 & 34.4 & 24.3 & 8.2 \\
-0.6 & 9.4 & 29.8 & 29.8 & 6.7 \\
-0.4 & 6.5 & 22.1 & 38.1 & 5.2 \\
-0.2 & 3.7 & 8.9 & 51.9 & 3.9 \\
0.0 & 1.5 & 0.1 & 72.2 & 2.8 \\
0.2 & 0.6 & 0.0 & 86.2 & 2.3 \\
0.4 & 0.4 & 0.0 & 91.6 & 2.2 \\
0.6 & 0.3 & 0.0 & 94.1 & 2.1 \\
0.8 & 0.2 & 0.0 & 95.5 & 2.1 \\
1.0 & 0.2 & 0.0 & 96.3 & 2.1
\end{tabular}

Table 1: Assuming a VR of 1.02, a $S D_{p}$ of 7.66 (based on Cipriani [10]) and different correlation coefficients $\rho$ between the response under placebo and the treatment effect. Left column ("any distribution"): Upper bounds for the standard deviation of the treatment effect. Right column ("dichotomous response"): Patients are either "non-responders" with a treatment effect of 0 , or "responders" with the responder treatment effect. For a given correlation coefficient $\rho$, there is one possible solution for this. TE: treatment effect. 
medRxiv preprint doi: https://doi.org/10.1101/2020.02.20.19015677; this version posted April 7, 2020. The copyright holder for this preprint (which was not certified by peer review) is the author/funder, who has granted medRxiv a license to display the preprint in perpetuity.

It is made available under a CC-BY 4.0 International license.

391 These results show that, contrary to intuition, a variability ratio of 1.02 is (theoretically)

392 compatible with a standard deviation of the treatment effect between 0 and 15.5. Conversely,

393 a reduction in the variability in the treatment group is compatible with a substantial treatment

394 effect heterogeneity if the response under placebo is correlated with the individual treatment

395 effect (see simulations in supplementary file, figures 8 and 9).

396

397 Simulations

398 We conducted simulation experiments in order to illustrate the compatibility of a VR of 1.02

399 with different degrees of treatment effect heterogeneity. For a large treatment effect

400 heterogeneity, the individual treatment effect was drawn from a distribution with an (arbitrarily

401 chosen) standard deviation $\mathrm{SD}_{\mathrm{TE}}=6.5 \mathrm{HAMD}-17$. For this $\mathrm{SD}_{\mathrm{TE}}$, the response under placebo

402 and the individual treatment effect have to be correlated by the correlation factor $\rho=-0.4$, in

403 order for the VR to credibly remain at or below 1.02 (see table 1). Figure 5 depicts the

404 change scores of 1000 patients under placebo (blue) and under active treatment (red). Here,

405 positive values denote an improvement of the depression severity.

406 Conversely, if the correlation factor $\rho$ is equal to 0 , a large treatment effect heterogeneity with

$407 \mathrm{SD}_{\mathrm{TE}}=6.5$ would yield a VR in the magnitude of 1.3. For the VR to be credibly lower than

$408 \quad 1.02$ and the response under placebo and the individual treatment effect to be uncorrelated

$409(\rho=0)$, the treatment effect heterogeneity has to be low. Supplementary figures 6 and 7

410 depict the results of such a simulated experiment. Here, the treatment effect heterogeneity

411 was imputed to be $S D_{T E}=1.5$ points on the HAMD-17 (derived from table 1). A VR closer to

4121 would yield an even smaller treatment effect heterogeneity.

413 
medRxiv preprint doi: https://doi.org/10.1101/2020.02.20.19015677; this version posted April 7, 2020. The copyright holder for this preprint (which was not certified by peer review) is the author/funder, who has granted medRxiv a license to display the preprint in perpetuity.

It is made available under a CC-BY 4.0 International license .

Histogram of potential outcome response under placebo and active treatment

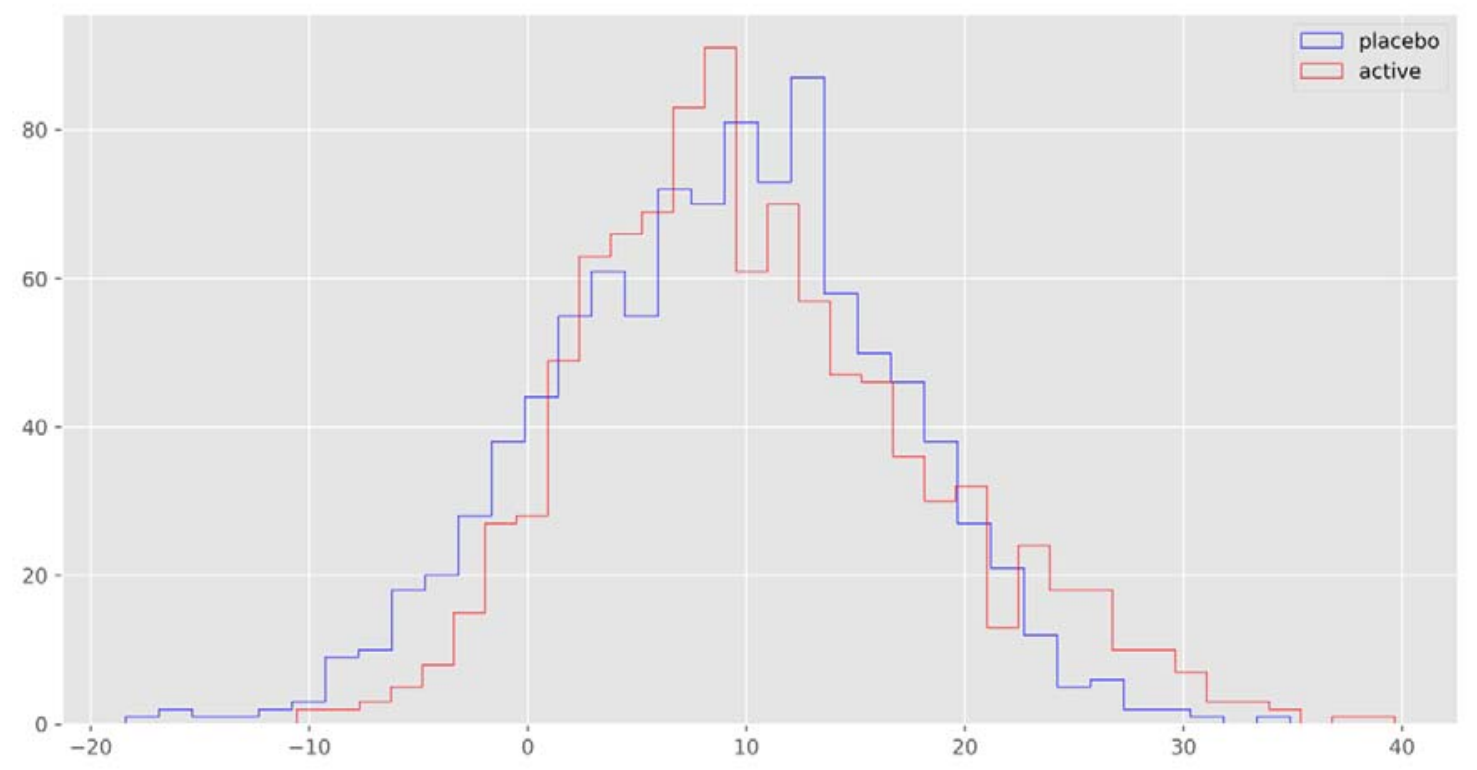

414

Potential outcome responses with baseline gauged to 0
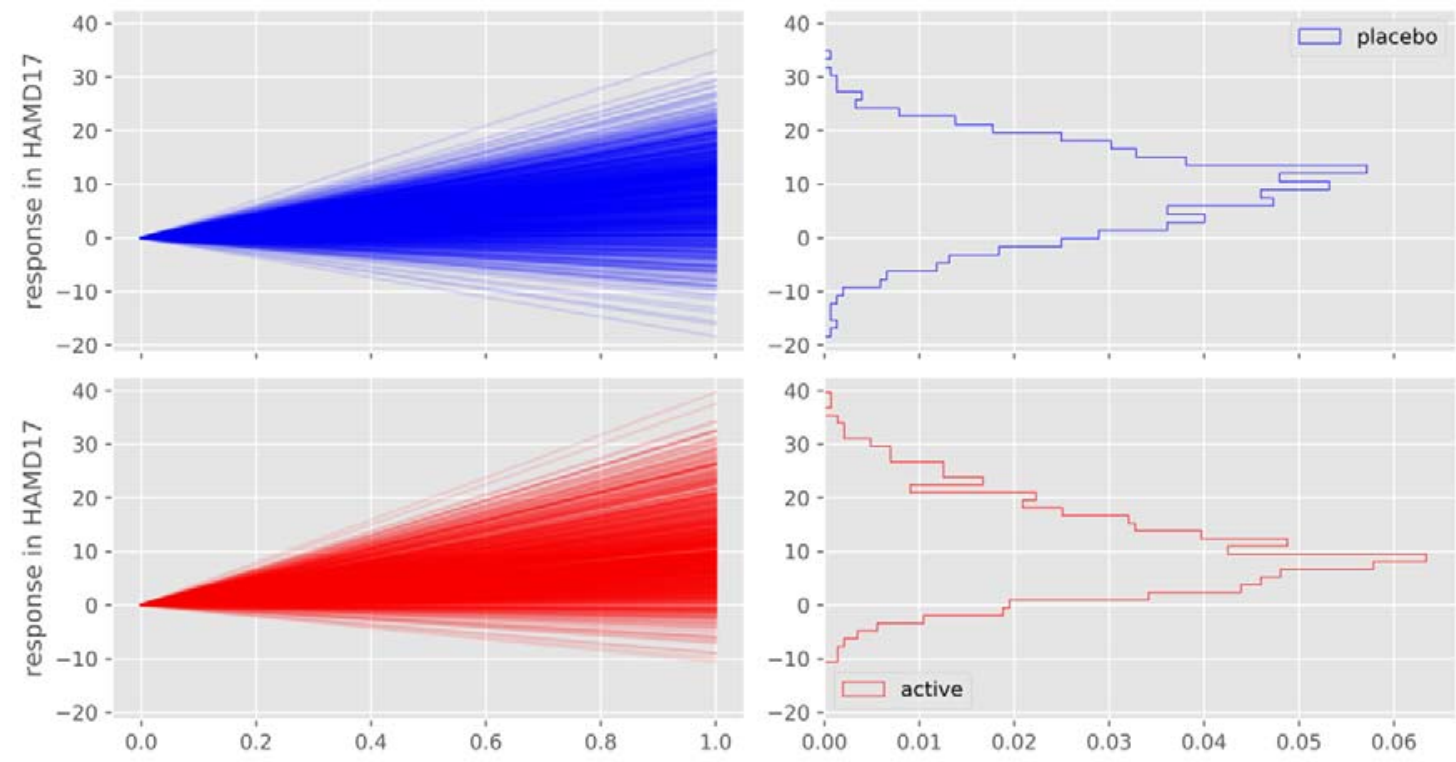

416 Figure 5: Change score of 1000 simulated patients under placebo (blue) and under active 417 treatment (red) for $\rho=-0.4, \mathrm{SD}_{\mathrm{TE}}=6.35 \mathrm{HAMD}-17$ points and $\mathrm{VR}=1.02$. Note, that in this 418 particular simulation, the $\mathrm{SD}_{\mathrm{TE}}$ is not exactly equal to 6.5 , as all simulations contain random processes.

420

421 Figure 6 shows the magnitude of the individual treatment effect of 100 individuals of this 422 simulation experiment. The values on the left $(x=0.0)$ denote the response under placebo of 423 all 100 patients, the values on the right $(x=1.0)$ represent the response under active 
medRxiv preprint doi: https://doi.org/10.1101/2020.02.20.19015677; this version posted April 7, 2020. The copyright holder for this preprint (which was not certified by peer review) is the author/funder, who has granted medRxiv a license to display the preprint in perpetuity.

It is made available under a CC-BY 4.0 International license .

424 treatment and the difference between the two values corresponds to the individual treatment 425 effect of a patient. As can be seen in the figure, for a large treatment effect heterogeneity to 426 be compatible with a VR of 1.02 , the response under placebo and the individual treatment 427 effect have to be correlated. Specifically, patients that would remain unchanged under 428 placebo (response close to 0 at $\mathrm{x}=0.0$ ) have a larger benefit from active medication (higher density of blue slopes) than patients that would have improved under placebo (response above 0 at $x=0.0$ ). For some patients to benefit substantially, however, other patients have

431 to be harmed by the medication (red slopes).

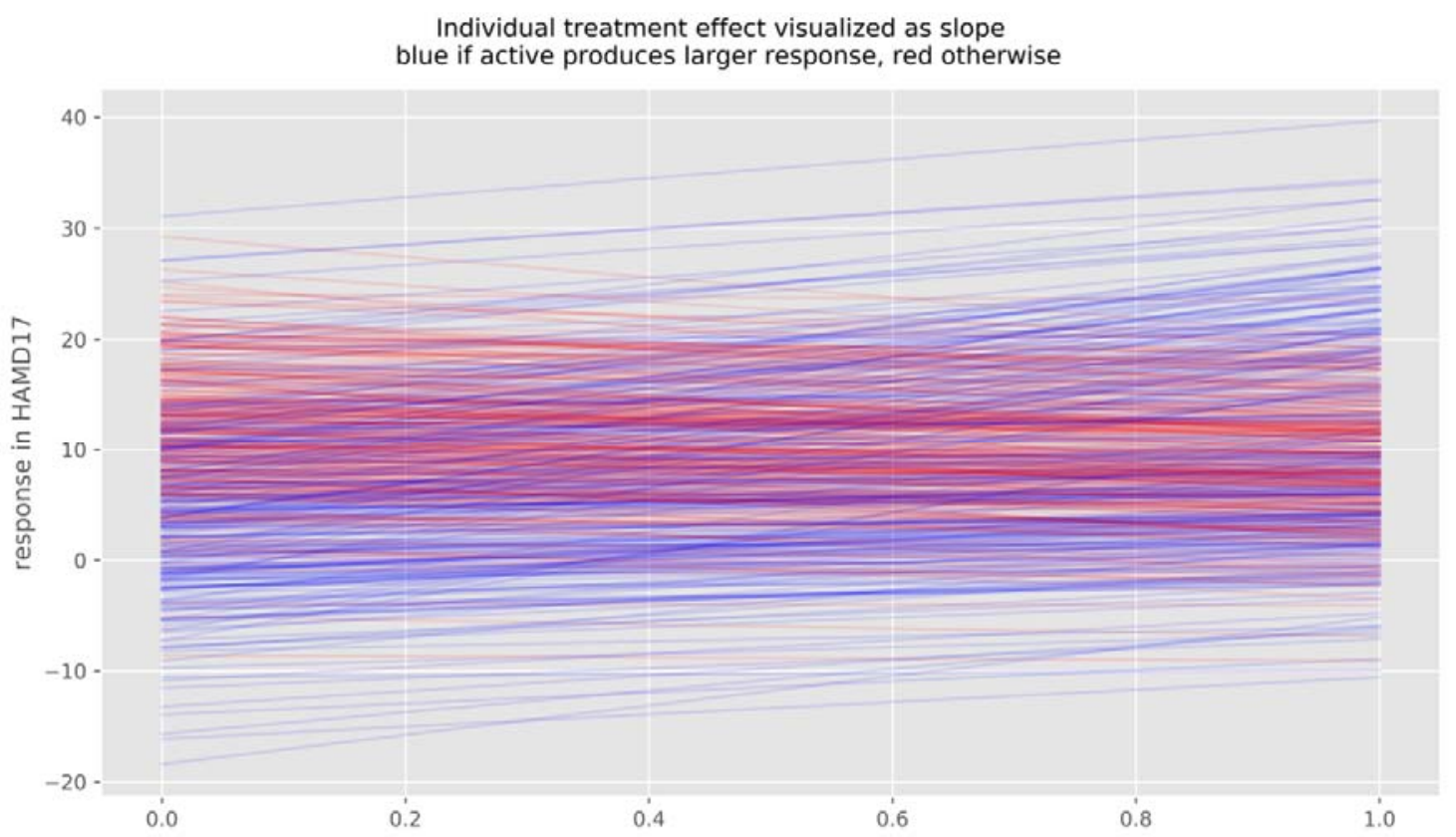

433 Figure 6: Potential outcomes and individual treatment effect of 100 simulated patients. Value 434 at $\mathrm{x}=0$ depicts response under placebo, value at $\mathrm{x}=1$ response under active treatment. 435 Slopes represent individual treatment effect, which varies substantially in this simulation. 436 Blue lines indicated improvement under active treatment, red lines deterioration.

\section{Discussion}

440

441 The efficacy of antidepressants in the treatment of major depressive disorder has been the 442 topic of an ongoing debate for years in the psychiatric community and the public [6-9]. In a 443 recent re-analysis [12] of a network meta-analysis [10], the average treatment effect of 444 antidepressants was found to be about 2 points on the HAMD-17 scale, which is almost 445 undetectable by clinicians [14] and clearly lies below the assumed minimally clinically 446 relevant effect of 7 points [16]. In addition, it should be noted that relevant biases may have 
medRxiv preprint doi: https://doi.org/10.1101/2020.02.20.19015677; this version posted April 7, 2020. The copyright holder for this preprint (which was not certified by peer review) is the author/funder, who has granted medRxiv a license to display the preprint in perpetuity.

It is made available under a CC-BY 4.0 International license .

447 led to an overestimation of the drugs' efficacy [12, 33]. Jakobsen et al. recently concluded

448 that, based on current evidence, antidepressants should not be used in adult patients with

449 major depressive disorder [34].

450

Evidence for treatment effect heterogeneity

452 On the basis of these facts, the question arises as to why these compounds are considered

453 to be effective, nevertheless. The main reason for this might be the assumption of a

454 substantial treatment effect heterogeneity, meaning that subpopulations of patients exist that

455 benefit substantially more than average from the medication. If the treatment effect

456 heterogeneity is low, no patient would have a clinically relevant benefit. In the face of the well

457 documented harms and side effects, antidepressants may then not be considered useful in

458 the treatment of major depression.

459 Albeit widely believed and putatively observed in clinical routine, substantial differences in

460 the individual treatment effect of antidepressants have not been shown to exist yet. A

461 "responder", usually defined as someone crossing an arbitrary threshold of symptom

462 severity, is a person who was observed to improve and not necessarily caused by the

463 medication to get better. Even constant treatment effects lead to differences in observed

464 response rates, creating the illusion of a differential treatment effect, where none exists [20].

465 Therefore, the frequently performed calculation of response rates is misleading and seems

466 inappropriate to answer the question of treatment effect heterogeneity.

467 This work aimed to estimate the treatment effect heterogeneity of antidepressants in the 468 treatment of major depressive disorder using a large dataset of a recent network meta-

469 analysis [10]. To this end, we applied the effect size statistics InVR and InCVR suggested by

470 Nakagawa et al. [28], using a Bayesian random-effects meta-analytical approach (REMA)

471 and fitted a multi-level meta-regression (REMR) model to estimate the treatment effect

472 variability between antidepressants and placebo. Both the InVR REMR and the InVR REMA,

473 which were found to outperform the InCVR REMA, showed that the variability ratio was very

474 close to 1 (REMR: 95\% HPD [0.98, 1.02], REMA: 95\% HPD [1.00, 1.02]), perfectly

475 compatible with a near-constant effect of antidepressants on depression severity. These

476 findings are in line with those of a recently published meta-analysis of antidepressants using

477 the same dataset [35].

478

479 Methodological aspects

480 In order to determine the variability of the treatment response, the correlation between the 481 mean and standard deviation of the underlying measuring scale has to be taken into account.

482 The InVR and the InCVR effect sizes naively assume a slope coefficient of 0 and 1 , 483 respectively. In other words, how much of the (logarithmic) difference in variances is 
medRxiv preprint doi: https://doi.org/10.1101/2020.02.20.19015677; this version posted April 7, 2020. The copyright holder for this preprint

484 explained by the difference in (logarithmic) means. Both scales may thus give biased results, 485 if the true slope coefficient differs from the one assumed.

486 By applying a varying intercept model, taking into account the occurrence of different 487 depression scales, we could show that the correlation between (logarithmic) mean and 488 (logarithmic) standard deviation is of a small magnitude (slope coefficient $=0.10$ ), indicating 489 that the InVR is a more appropriate measure as opposed to the InCVR. A regression over all 490 depression scales yields a slope coefficient of 0.25 , which is $2.5 \mathrm{x}$ as large as our estimate.

491 When simply conducting a significance test for the existence of such correlation, the InCVR 492 effect size would appear to be the appropriate measure, leading to the incorrect conclusion 493 of a substantially reduced variability in the active arm. It is important to note that a VR (or 494 CVR) sufficiently smaller than 1 is in fact evidence of relevant treatment effect heterogeneity 495 (see supplementary figure 8 and 9). Therefore, considering the InCVR as the main outcome 496 would lead to the opposite conclusion of substantial treatment effect heterogeneity [36].

497 Our work adds accuracy to the existing literature, as we developed a generalized model 498 (REMR) that incorporates the slope coefficient for the correlation between mean and 499 standard deviation directly from the data. This approach yielded a mean estimate for the VR 500 of 1.00 (95\% HPD [0.98,1.02]), again compatible with a near-constant effect.

501 We applied the WAIC in order to estimate the predictive power of our models. This effect 502 measure showed that the models using the InVR effect size had a better out of sample 503 predictive power than the models using the InCVR effect size.

Upper bound for the treatment effect heterogeneity

506 As a relevant treatment effect heterogeneity cannot be ruled out even with a variability ratio

507 near 1, we aimed at estimating the upper bound in treatment effect variation compatible with 508 our results. We were able to analytically derive an inequality that provides an upper bound 509 for the treatment effect heterogeneity, taking into account a possible correlation between the 510 placebo response and the individual treatment effect. We could show that a VR of 1.02 (the 511 upper bound of the 95\% HPD interval of the REMR) is theoretically compatible with a 512 standard deviation of the treatment effect between 0 and 15.5 points on the HAMD-17 scale, 513 translating into a maximum of $37 \%$ of patients with an individual treatment effect of more 514 than 7 points on the HAMD-17 scale.

515 However, such a large standard deviation and hence treatment effect heterogeneity would 516 require the treatment effect and the response under placebo of a patient to be strongly and 517 negatively correlated in order to be compatible with a VR of 1.02. If no such correlation 518 exists, the treatment effect heterogeneity would be negligibly small ( $S D_{T E}=1.5 \mathrm{HAMD}-17$ 519 points, $0.1 \%$ of patients benefitting more than 7 points on the HAMD-17 scale). 
medRxiv preprint doi: https://doi.org/10.1101/2020.02.20.19015677; this version posted April 7, 2020. The copyright holder for this preprint (which was not certified by peer review) is the author/funder, who has granted medRxiv a license to display the preprint in perpetuity.

It is made available under a CC-BY 4.0 International license .

520 As only one outcome per patient (either under placebo or under active treatment; figure 1)

521 can be measured in a real experiment, the true correlation $\rho$ between the response under

522 placebo and the treatment effect cannot be derived from RCT data.

523

524

How should these results be interpreted?

525 The VR is a measure that can potentially detect evidence for subgroups that benefit

526 (substantially) more than average from an intervention. A VR that differs substantially from 1

527 is evidence of such subgroups (of large treatment effect heterogeneity), while a VR near 1 is

528 compatible with both a small and a large treatment effect heterogeneity. A VR of exactly 1

529 (which is the mean-estimate of our REMR model) would be proof of a constant treatment

530 effect. It is, however, impossible to ever prove identity, as we can never reach an uncertainty

531 of 0 (credible interval with width of 0 ). Furthermore, an exactly constant treatment effect

532 seems impossible also from a theoretical point of view. So how should a VR of 1 (95\% HPD

$533[0.98,1.02])$ be interpreted? For this, consider the following illustration:

534

535 Hypothesis $1(H 1)$ : The treatment effect heterogeneity is close to 0 (e.g. $99 \%$ of patients

536 have an individual treatment effect of 1 to 3 HAMD points).

537 Hypothesis $2(\mathrm{H} 2)$ : The treatment effect heterogeneity is greater than in $\mathrm{H} 1$.

538

539 There are now three possibilities:

540 1. $\mathrm{H} 1$ is true and $\mathrm{VR} \approx 1$ (very close to 1 , e.g. 0.98 to 1.02 )

541 2. $\mathrm{H} 2$ is true and $V R \approx 1$

$542 \quad 3 . \mathrm{H} 2$ is true and $\mathrm{VR} \neq 1$ (not very close to 1 )

543

544 Our results indicate that $V R \approx 1$. We can thus rule out one of the three possibilities, namely a

545 large treatment heterogeneity combined with a VR $\neq 1$. From a Bayesian perspective, the

546 probability of $\mathrm{H} 1$ being true increases, while that of $\mathrm{H} 2$ being true decreases. How we now

547 regard the probability of $\mathrm{H} 1$ or $\mathrm{H} 2$ being true depends on how plausible we considered these

548 scenarios to begin with (the prior probabilities).

549 In order for $\mathrm{H} 2$ to be true and the VR being close to 1, strong assumptions regarding

550 the correlation between the placebo response and the individual treatment effect of

551 antidepressants are necessary. Specifically, those patients whose depression severity would

552 remain unchanged under placebo would need to have the strongest antidepressant

553 medication effect. If this were the case, we might expect patients with certain features (such

554 as chronic depression) to benefit substantially more than average from

555 antidepressants. Since no such subpopulations have been identified to date, such a 
medRxiv preprint doi: https://doi.org/10.1101/2020.02.20.19015677; this version posted April 7, 2020. The copyright holder for this preprint (which was not certified by peer review) is the author/funder, who has granted medRxiv a license to display the preprint in perpetuity.

It is made available under a CC-BY 4.0 International license .

556 correlation seems unlikely. If no such correlation is assumed, a VR of 1.02 indicates a low

557 degree of treatment effect heterogeneity.

558

559 Conclusion

560 By applying a multiple level Bayesian regression model and simulations, this work could 561 show that the published data on antidepressants in the treatment of major depression is 562 compatible with a near-constant treatment effect, which is also the simplest explanation for 563 the observed data. Although is not possible to rule out a substantial treatment effect 564 heterogeneity using summary data from RCTs, we could show that a substantial treatment 565 effect heterogeneity is only compatible with the published data under strong assumptions 566 that seem rather unlikely. Until the existence of benefiting subgroups has been demonstrated 567 prospectively, the average treatment effect is the best estimator for the individual treatment 568 effect. Since the average treatment effect of antidepressants probably falls short of clinical 569 relevance, the current prescribing practice in the treatment of major depression should be 570 critically re-evaluated.

571

572

573

Python code

574 https://github.com/volkale/advr

575

576 Statement of Ethics

577 The authors have no ethical conflicts to disclose.

578

579

Disclosure Statement

580 CAM received consulting fees from Silence Therapeutics, outside the submitted work. The 581 other authors declared no competing interest. All authors declare no other relationships or 582 activities that could appear to have influenced the submitted work. No funder had any role in:

583 the design and conduct of the study; collection, management, analysis, and interpretation of

584 the data; preparation, review, or approval of the manuscript; and decision to submit the 585 manuscript for publication.

586

587 Funding Sources

588 The authors received no specific funding for this work.

589

590 Author Contributions

591 Study idea and design: CV and CAM. Data extraction, statistical analyses, visualizations and

592 simulation experiments: AV and CV. Mathematical modelling, code implementation and 
medRxiv preprint doi: https://doi.org/10.1101/2020.02.20.19015677; this version posted April 7, 2020. The copyright holder for this preprint (which was not certified by peer review) is the author/funder, who has granted medRxiv a license to display the preprint in perpetuity.

It is made available under a CC-BY 4.0 International license .

593 derivation of formula: AV. All authors contributed to drafting the manuscript. All authors 594 provided a critical review and approved the final paper.

595 
medRxiv preprint doi: https://doi.org/10.1101/2020.02.20.19015677; this version posted April 7, 2020. The copyright holder for this preprint (which was not certified by peer review) is the author/funder, who has granted medRxiv a license to display the preprint in perpetuity.

\section{References}

597 1. WHO. Depression and Other Common Mental Disorders: Global Health

598

599

600

601

602

603

604

605

606

607

608

609

610

611

612

613

614

615

616

617

618

619

620

621

622

623

624

625

626

627

628

629

630

631

632

633

634

635

636

637

638

639

640

641

642

643

644 Estimates. 2017; Available from: https://apps.who.int/iris/bitstream/handle/10665/254610/WHO-MSD-MER2017.2-eng.pdf.

2. DGPPN, S3-Leitlinie und Nationale VersorgungsLeitlinie (NVL) Unipolare Depression, 2. Auflage. 2015.

3. NICE, Depression in adults: recognition and management. 2009. [28.08.2019] Available from: https://www.nice.org.uk/guidance/cg90/chapter/1Guidance\#treatment-choice-based-on-depression-subtypes-and-personalcharacteristics

4. BMJ, NHS prescribed record number of antidepressants last year, in BMJ. 2019. I1508.

5. Kantor, E.D., et al., Trends in Prescription Drug Use Among Adults in the United States From 1999-2012. JAMA, 2015. 314(17): p. 1818-31.

6. Moncrieff, J. and I. Kirsch, Efficacy of antidepressants in adults. BMJ, 2005. 331(7509): p. 155-7.

7. Fountoulakis, K.N. and H.J. Moller, Efficacy of antidepressants: a re-analysis and re-interpretation of the Kirsch data. Int J Neuropsychopharmacol, 2011. 14(3): p. 405-12.

8. Davis, J.M., et al., Should we treat depression with drugs or psychological interventions? A reply to loannidis. Philos Ethics Humanit Med, 2011. 6: p. 8.

9. Gotzsche, P.C., Why I think antidepressants cause more harm than good. Lancet Psychiatry, 2014. 1(2): p. 104-6.

10. Cipriani, A., et al., Comparative efficacy and acceptability of 21 antidepressant drugs for the acute treatment of adults with major depressive disorder: a systematic review and network meta-analysis. Lancet, 2018. 391(10128): p. 1357-1366.

11. BMJ, Large meta-analysis ends doubts about efficacy of antidepressants. 2018. k847.

12. Munkholm, K., A.S. Paludan-Muller, and K. Boesen, Considering the methodological limitations in the evidence base of antidepressants for depression: a reanalysis of a network meta-analysis. BMJ Open, 2019. 9(6): p. e024886.

13. Hamilton, M., Development of a rating scale for primary depressive illness. $\mathrm{Br}$ J Soc Clin Psychol, 1967. 6(4): p. 278-96.

14. Leucht, S., et al., What does the HAMD mean? J Affect Disord, 2013. 148(23): p. 243-8.

15. Guy, W., Clinical Global Impressions ECDEU Assessment Manual for Psychopharmacology, Revised (DHEW Publ. No. ADM 76-338). 1976, National Institute of Mental Health: Rockville, MD. p. 218-222.

16. Moncrieff, J. and I. Kirsch, Empirically derived criteria cast doubt on the clinical significance of antidepressant-placebo differences. Contemp Clin Trials, 2015. 43: p. 60-2.

17. BMJ, Effectiveness of antidepressants. 2018. k1073.

18. BMJ, The cost of dichotomising continuous variables. 2006. 1080.

19. Austin, P.C. and L.J. Brunner, Inflation of the type I error rate when a continuous confounding variable is categorized in logistic regression analyses. Stat Med, 2004. 23(7): p. 1159-78. 
medRxiv preprint doi: https://doi.org/10.1101/2020.02.20.19015677; this version posted April 7, 2020. The copyright holder for this preprint (which was not certified by peer review) is the author/funder, who has granted medRxiv a license to display the preprint in perpetuity. It is made available under a CC-BY 4.0 International license .

645 20. Senn, S., Statistical pitfalls of personalized medicine. Nature, 2018.

646

647

648

649

650

651

652

653

654

655

656

657

658

659

660

661

662

663

664

665

666

667

668

669

670

671

672

673

674

675

676

677

678

679

680

681

682

683

684

685

686

687

688

689

690

691

692

563(7733): p. 619-621.

21. Winkelbeiner, S., et al., Evaluation of Differences in Individual Treatment Response in Schizophrenia Spectrum Disorders: A Meta-analysis. JAMA Psychiatry, 2019.

22. Senn, S., Mastering variation: variance components and personalised medicine. Stat Med, 2016. 35(7): p. 966-77.

23. Fisher, R.A. and others, Statistical inference and analysis: Selected correspondence of ra fisher, edited by jh bennett. 1990: Oxford: Clarendon Press.

24. Montgomery, S.A. and M. Asberg, A new depression scale designed to be sensitive to change. Br J Psychiatry, 1979. 134: p. 382-9.

25. Rush, A.J., et al., Self-reported depressive symptom measures: sensitivity to detecting change in a randomized, controlled trial of chronically depressed, nonpsychotic outpatients. Neuropsychopharmacology, 2005. 30(2): p. 405-16.

26. Jefferson, J.W., et al., Extended-release bupropion for patients with major depressive disorder presenting with symptoms of reduced energy, pleasure, and interest: findings from a randomized, double-blind, placebo-controlled study. J Clin Psychiatry, 2006. 67(6): p. 865-73.

27. The Cochrane Collaboration, Cochrane Handbook for Systematic Reviews of Interventions Version 5.1.0. 2011 [02.09.2019]; Available from: www. handbook.cochrane.org.

28. Nakagawa, S., et al., Meta-analysis of variation: ecological and evolutionary applications and beyond. Methods in Ecology and Evolution, 2015. 6(2): p. 143-152.

29. McCutcheon, R.A., et al., The efficacy and heterogeneity of antipsychotic response in schizophrenia: A meta-analysis. Mol Psychiatry, 2019. doi: 10.1038/s41380-019-0502-5.

30. Leucht, S., et al., Translating the HAM-D into the MADRS and vice versa with equipercentile linking. J Affect Disord, 2018. 226: p. 326-331.

31. Vehtari, A., A. Gelman, and J. Gabry. Practical Bayesian model evaluation using leave-one-out cross-validation and WAIC. 2016. doi: 10.1007/s11222016-9696-4.

32 Volkmann, A. "A bound on the Treatment Effect Heterogeneity using estimates on the Variability Ratio", in preparation.

33. Hengartner, M.P., Methodological Flaws, Conflicts of Interest, and Scientific Fallacies: Implications for the Evaluation of Antidepressants' Efficacy and Harm. Front Psychiatry, 2017. 8: p. 275.

34. Jakobsen, J.C., C. Gluud, and I. Kirsch, Should antidepressants be used for major depressive disorder? BMJ Evid Based Med, 2019. doi: 10.1136/bmjebm-2019-111238.

35. Plöderl, M. and M.P. Hengartner, Can we expect that some patients respond better to antidepressants? A secondary variance-ratio meta-analysis. 2019. osf.io/98kex.

36. Maslej, M.M., et al., Individual Differences in Response to Antidepressants: A Metaanalysis of Placebo-Controlled Randomized Clinical Trials. JAMA Psychiatry, 2020. DOI: 10.1001/jamapsychiatry.2019.4815 